\title{
CORRIGENDUM \\ Reynolds-number effects and anisotropy in transverse-jet mixing - CORRIGENDUM
}

\author{
JERRY W. SHAN AND PAUL E. DIMOTAKIS
}

doi:10.1017/S0022112006001224, Published by Cambridge University Press,

5 October 2006

In Shan \& Dimotakis (2006), the Schmidt number was incorrectly stated as 2800 on p. 60. The correct value, calculated from the diffusivity of rhodamine- $6 \mathrm{~g}$ given in Xu \& Yeung (1997) should be 3570. This also affected values in the right-most column of table 1 . The correct table should appear as follows.

\begin{tabular}{cclcrrc}
$R e_{j}$ & $V_{r}$ & $\Theta / d_{j}$ & \multicolumn{1}{c}{$R e_{\Gamma}$} & $R e_{\lambda}$ & $\lambda_{\nu} / \lambda_{p}$ & $\lambda_{\mathscr{D}} / \lambda_{p}$ \\
$1.0 \times 10^{3}$ & 10 & 0.30 & $0.58 \times 10^{3}$ & 32 & 281 & 4.7 \\
$2.0 \times 10^{3}$ & 10 & 0.21 & $1.2 \times 10^{3}$ & 45 & 167 & 2.8 \\
$5.0 \times 10^{3}$ & 10 & 0.13 & $2.9 \times 10^{3}$ & 71 & 84 & 1.4 \\
$10 \times 10^{3}$ & 10 & 0.094 & $5.8 \times 10^{3}$ & 100 & 50 & 0.84 \\
$20 \times 10^{3}$ & 10 & 0.067 & $12 \times 10^{3}$ & 141 & 30 & 0.50
\end{tabular}

TABLE 1. Experimental conditions and imaging resolution of the LIF measurements at $x / d_{j}=50 . \lambda_{p}$ is the in-plane pixel resolution for the transverse slices. The momentum thickness, $\Theta$, is computed at the jet exit. The circulation-based $\left(R e_{\Gamma}\right)$ and Taylor $\left(R e_{\lambda}\right)$ Reynolds numbers are computed at $x / d_{j}=50$.

We thank Dongjin Kim, Georgia Institute of Technology, for bringing the error to our attention.

\section{REFERENCE}

XU, X.-H. \& Yeung, E. S. 1997 Direct measurement of single-molecule diffusion and photo-decomposition in free solution. Science 275, 1106-1109. 